Преводна статия от Европейското списание по болнична фармация, пъбликувана след разрешение на Европейската асоциаџия на болничните фармащевти (ЕАНР)

\title{
ESTIMATING THE REQUIREMENT FOR MANIPULATION OF MEDICINES TO PROVIDE ACCURATE DOSES FOR CHILDREN
}

\author{
A. Nunn ${ }^{1}$, R. Richey ${ }^{1}$, U. Shah ${ }^{2,3}$, C. Barker ${ }^{3,4}$, J. Craig ${ }^{5}$, M. Peak ${ }^{1,3}$, J. Ford ${ }^{2}$ and M. Turner ${ }^{6,7}$ \\ ${ }^{1}$ Research and Development, Alder Hey Children's NHS Foundation Trust, Liverpool, UK; ${ }^{2}$ School of Pharmacy and Bio- \\ medical Sciences, Liverpool John Moores University, Liverpool, UK; ${ }^{3}$ Cheshire and Merseyside Medicines for Children \\ Research Network, Alder Hey Children's NHS Trust, Liverpool, UK; ${ }^{4}$ Department of Pharmacy, Alder Hey Children's NHS \\ Foundation Trust, Liverpool, UK; ${ }^{5}$ School of Medicine, Health Policy and Practice, University of East Anglia, Norwich, \\ UK; ${ }^{6}$ Division of Perinatal and Reproductive Medicine, University of Liverpool, Liverpool, UK; ${ }^{7}$ NIHR Medicines for \\ Children Research Network, NIHR Medicines for Children Research Network,; University of Liverpool, Liverpool, UK
}

\section{ОЦЕНЯВАНЕ НА НЕОБХОДИМОСТТА ЗА КОРЕКЦИЯ НА КОЛИЧЕСТВОТО НА ЛЕКАРСТВАТА ЗА ПОСТИГАНЕ НА ТОЧНА ДОЗИРОВКА ЗА ДЕЦА}

\section{А. Нън ${ }^{1}$, Р. Ричи ${ }^{1}$ У. Шах}

Изследователска и развойна дейност, Тръст „Детска фондация на Националната здравна служба, Ливърпул, Великобритания, Британски институт за фармация и медицински науки, Ливърпулски университет „Джон Мурс“, Ливърпул, Великобритания, Изследователска мрежа за детска медииина Чешър и Мърсисайд, Великобритания, Тръст ,Детска фондация на Наџионалната здравна служба „Алдър Хей“, Ливърпул, Великобритания, Катедра „, Фармация“, Тръст „Детска фондация на Наџионалната здравна служба „Алдър Хей“, Ливърпул, Великобритания, Институт по медицина, здравна политика и практика, Университет Ийст Англия, Норич, Великобритания, сектор „Перинатална и репродуктивна медицина“, Университет Ливърпул, Ливърпул, Великобритания, Изследователска мрежа „Лекарства за деца “, Национален институт за здравни изследвания, Изследователска мрежа „Лекарства за деца“",

Национален институт за здравни изследвания, Университет Ливърпул, Ливърпул, Великобритания

\section{Цел}

Определяне на вида и честотата на корекция на дозовите форми за даване на по-малки дози на деца и съответните лекарства, предмет на контролирано приложение.

\section{МЕтоди}

Опитен педиатричен клиничен фармацевт оцени необходимостта за корекция на лекарства за даване на прецизна дозировка въз основа на данни от рецепти за всички хоспитализирани пациенти в отделения „Неонатология“ и „Детско“, събрани за периоди от пет дни и информация за наличието на дозови форми в районна детска болница (РДБ) и районен педиатричен корпус за интензивна терапия (РПКИТ), регионален неонатологичен корпус за интензивна терапия (РНКИТ) и детски и неонатологични отделения в окръжни многопрофилни болни- ци (ОМБ), използващи системи за предписване на лекарства на хартиен носител. Беше предоставена наличност от готови за приложение интравенозни лекарства в отделенията. Главните изходящи измерени показатели бяха оценената необходимост за корекция на лекарствената форма, видът корекция и наименованието на лекарствения продукт.

\section{РезУлтати}

От 5375 оценени предписания на лекарства, при 542 (10.1\%) беше преценено, че е необходима корекция или отмерване на мальк обем $(<0.2 \mathrm{ml})$. Най-честата корекция беше отмерване на доза за орално приложение в обеми от 0.1 до $<0.2 \mathrm{ml}$ в ОМБ. $25.2 \%$ от всички корекции бяха заради необходимост от отмерване на дози по-малки от $0.1 \mathrm{ml}$ (за орално и интравенозно приложение), като необходимостта от отмерване на дози за интравенозно приложение в обем по-мальк от 
$0.1 \mathrm{ml}$ бяха най-чести в РНКИТ и РПКИТ (съответно $60.4 \%$ и $31.9 \%$ от корекциите). Лекарственият продукт, за който се установи, че най-често е необходима корекция, беше хидрокортизоньт, както за измерване на малки обеми за интравенозно инжектиране (РПКИТ и РНКИТ), така и за разделяне на таблетки (РДБ).

\section{Изводи}

Корекцията на дозата на лекарства (в т.ч. отмерване на много малки обеми) за осигуряване на прецизни малки дозировки за деца е често срещано явление в болнични условия.

\section{ВЪВЕДЕНИЕ}

Много от лекарствата, използвани за бебета и деца, все още не са лицензирани за тази цел и тяхната употреба се счита за приложение на лекарствения продукт извьн кратката характеристика (off-lable) [1]. Лекарствената форма (напр. таблетка, капсула, инжекция) обикновено е предназначена за използване при възрастни хора и може да не е ,подходяща предвид възрастта“ за дете. Например дозата, необходима за дете, може да се съдържа в една част от таблетката или високата концентрация на лекарството в инжекцията може да означава, че педиатричната дозировка не може да бъде прецизно отмерена без предварително разреждане [2]. Дори когато едно лекарство е разрешено за употреба при бебета и деца, лекарствената форма може да не е съобразена с възрастта [3]. Така коригирането на дозовата форма например чрез разделяне на таблетки или разреждане на инжекции може да се предприема с цел прецизно приложение на предписаната дозировка на дете. Има риск приложената доза да не бъде прецизна и да се появят лекарствени грешки при изчисляването и приготвянето на дозировката [4]. Данните относно степента на корекция на дозите в педиатричната практика, точността, с която лекарствените форми могат да бъдат коригирани или лекарствата, които най-често са предмет на това, са оскъдни $[5,6]$.

Замисьльт при създаването на набора проекти, обединени под заглавие MODRIC (Manipulation of Drugs Required in Children - „Корекция на дозите на лекарства, необходими за деца) [2] беше осигуряване на систематичен преглед на приложимата литература, наблюдение и изследване на практиката, оценяване на риска и разработване на указания. Настоящото проучване е част от изследването MODRIC и цели оценяването на вида и честотата на корекциите, както и съответните лекарства, предмет на корекции, в районна детска болница (РДБ), районен неонатологичен корпус за интензивна терапия (РНКИТ) и в детски и неонатологични отделения в окръжна многопрофилна болница (ОМБ).

\section{МЕтоди}

В настоящото изследване „корекция“ се дефинира като физическото променяне на дозовата форма в момента на приложението на лекарството за целите на осигуряване и прилагане на част от дозата, оригинално съдържана в дозовата форма. Таблица 1 представя описание на най-често срещаните корекции.

Таблица 1. Описание на корекцичте на дозови форми за осигуряване на прецизно прилагане на по-малки дози на деца

\begin{tabular}{|c|c|c|}
\hline Дозова форма & $\begin{array}{l}\text { Корекцията на дозата за } \\
\text { прецизност включва: }\end{array}$ & \\
\hline \multirow{3}{*}{ Таблетка } & A. & Разделяне/разчупване/разрязване и даване на парченце; или \\
\hline & B. & Стриване и даване на част от таблетката на прах; или \\
\hline & C. & Разтваряне във вода и даване на част от дисперсията. \\
\hline \multirow[t]{2}{*}{ Капсула } & A. & Отваряне, разтваряне във вода и даване на част от дисперсията; или \\
\hline & B. & Отваряне и даване на част от веществото на прах. \\
\hline \multirow[t]{2}{*}{ Саше (прахообразна форма) } & A. & Отваряне, разтваряне във вода и даване на част от дисперсията; или \\
\hline & B. & Отваряне и даване на част от веществото на прах. \\
\hline \multirow[t]{2}{*}{ Течна форма за орална употреба } & A. & Разреждане и даване на част от течността (за по-лесно отмерване на дозировка в по-малък обем) \\
\hline & B. & Опити за прилагане на много малки дози $(0.1 \mathrm{ml}$ и $0.1 \mathrm{ml}$ до < $0.2 \mathrm{ml})$ също бяха отчетени \\
\hline \multirow[t]{2}{*}{ Разтвор за небулизатор } & A. & Даване на част; или \\
\hline & B. & Разреждане и даване на част. \\
\hline \multirow[t]{2}{*}{ Промивка за клизма/мехур } & A. & Даване на част от сашето/единичната доза (като остатъкът се изхвърля след това); или \\
\hline & B. & Отстраняване на част от съдържанието и даване на останалото. \\
\hline \multirow[t]{2}{*}{ Трансдермален пластир } & A. & Разрязване на пластира и поставяне на част от него; или \\
\hline & B. & Отваряне на част от пластира и поставянето му. \\
\hline \multirow[t]{4}{*}{ Интравенозно инжектиране } & A. & $\begin{array}{l}\text { Допълнително разреждане на приготвения разтвор или разтвор в готова форма за отмерване } \\
\text { на по-малка доза; или }\end{array}$ \\
\hline & B. & $\begin{array}{l}\text { Отстраняване на част от течността от контейнера за интравенозно приложение, добавяне на } \\
\text { медикамент (за получаване на прецизна концентрация за вливане). }\end{array}$ \\
\hline & C. & Добавяне на медикамент към сака за инфузия, отстраняване на пропорция с по-малка доза и вливане. \\
\hline & D. & Бяха отчетени и опити за администриране на много малки обеми (0.1 ml и 0.1 ml до < 0.2 ml). \\
\hline
\end{tabular}


Коригирането на дозовите форми единствено за удобство при прилагането (напр. стриване на цяла таблетка, разтваряне във вода или смесване с храна и прилагане орално) не е предмет на настоящата студия. Изготвянето на магистрални или фармакопейни лекарства в болнична аптека (често за избягване на коригиране в момента на приложението) просто не се счита за корекция.

Отмерването на много малки обеми за инжектиране или орално приложение на течности (класифицирани в граници $<0.1 \mathrm{ml}$ и от 0.1 до $<2.0 \mathrm{ml}$ ) също са включени, тъй като дозовата форма (течност за инжекционно или орално приложение) често бива разреждана за постигането на прецизно отмерване на обема.

Бяха проучени всички рецепти на хоспитализирани пациенти, издадени чрез система за рецепти на хартия, в продължение на три петдневни периода в РДБ (309 легла, в т.ч. 15 легла от интензивен сектор), ОМБ с детски отделения (26 легла) и отделение „Неонатология“ (16 креватчета, вкл. 3 за интензивна терапия) и в РНКИТ (48 креватчета, в т.ч. 18 за интензивна терапия) в периода февруари - юни 2011 г. Използвани бяха модели за доставка на лекарства, налични в отделението, като за отделни пациенти се доставяха лекарства извън наличностите на отделението от аптеката. Някои инжекционни лекарства (напр. антибиотици в РДБ) и инфузии (напр. допамин, добутамин в РПКИТ) бяха изготвяни във вид готов за приложение от аптеката. Фармацевти с изследователски функции и сестри записваха данните за предписваните и прилаганите лекарства, в т.ч. наименование на лекарството, дозировка, начин и честота на приложението. Опитен клиничен фармацевт в областта на педиатрията определяше дали е необходимо коригиране, за да се даде предписаната доза от дозовите форми и концентрации, за които беше известно, че са налични в болниците. В случай че се знаеше, че има лекарствен продукт, подходящ за възрастта (в т.ч. магистрални или фармакопейни лекарства), се приемаше, че именно той е използван.
Данните за РПКИТ (ниво на медицински грижи 4, 23 легла) в РДБ бяха записвани и анализирани отделно.

В случай на недостатъчна информация, за да се определи дали е необходима корекция, прилагането на съответното лекарство се отбелязваше като неподлежащо на оценяване. Всички данни бяха анонимизирани.

\section{Резултати}

Бяха записани общо 5495 прилагания на лекарства в рамките на петдневните периоди; 120 от прилаганията (2.2\%) бяха неподлежащи на оценяване, с което се получиха 5375 за оценяване. За $542(10.1 \%)$ от тях се прецени, че е необходима корекция съгласно определението.

Броят корекции във всеки отделен вид обект за медицински грижи е показан в Таблица 2. В РДБ (РДБ + РПКИТ) корекциите бяха 339 с 3633 дозирания, подлежащи на оценяване (9.3\%). Установи се, че найголемият дял корекции беше необходим в ОМБ. Един вид приложение (доза за орален прием 0.1 до $<2.0 \mathrm{ml}$ домперидон, ранитидин и токоферол) възлезе на 107 бр. (71\%) от корекциите, извършени в тези условия.

Видовете корекции, за които беше преценено, че са необходими в различните условия на болнична грижа - неонатология и педиатрия, са показани в Таблица 3. Като цяло най-честата корекция беше за отмерване на доза за орално приложение в обеми от 0.1 до под $0.2 \mathrm{ml}$, като най-много това се налагаше в ОМБ. Необходимостта за отмерване на дози по-малки от $0.1 \mathrm{ml}$ (за орално и интравенозно приложение) съставляваха $25.2 \%$ от всички корекции, като необходимостта за отмерване на дозировки за интравенозен път по-малки от $0.1 \mathrm{ml}$ бяха най-често срещани в РНКИТ и РПКИТ (съответно 60.4\% и $31.9 \%$ ). Също така често беше наложително да се отмерват обеми за интравенозно инжектиране от 0.1 $\mathrm{ml}$ до под $0.2 \mathrm{ml}$ за тези два типа условия (съответно $34.0 \%$ и $40.4 \%)$.

Таблица 2. Брой и дял на корекциите в условия на педиатрична/неонатологична болнична грижа (петдневни периоди)

\begin{tabular}{|l|l|l|l|l|}
\hline Болнични условия & Общо записани дозирания & Общо дозирания, подлежащи на оценяване & Общо корекции & \% корекции \\
\hline РНКИТ & 825 & 820 & 53 & 6.5 \\
\hline ОМБ & 922 & 922 & 150 & 16.3 \\
\hline РПКИТ & 1761 & 1689 & 213 & 12.6 \\
\hline РДБ & 1987 & 5374 & 126 & 6.5 \\
\hline Общо & 5495 & 542 & 10.1 \\
\hline
\end{tabular}

*120 (2.2\%) от отчетените дозирания не можеха да бъдат оценени.

ОМБ - окрьжна многопрофилна болница; РДБ - районна детска болница; РПКИТ - районен педиатричен корпус за интензивна терапия; РНКИТ - районен неонатологичен корпус за интензивна терапия. 
Таблица 3. Видове манипулации по вид болнични условия (неонатологични/детски)

\begin{tabular}{|c|c|c|c|c|c|c|c|c|c|c|c|c|c|c|c|c|c|c|c|c|c|c|}
\hline 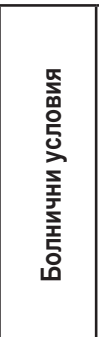 & $\begin{array}{l}\frac{5}{\Sigma} \\
\bar{c} \\
\mathbf{v} \\
\underline{m}\end{array}$ & $\stackrel{t}{\circ}$ & 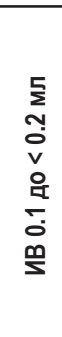 & to & $\begin{array}{l}\frac{5}{2} \\
\frac{1}{0} \\
\text { v } \\
\text { 오 } \\
\text { 总 } \\
\text { o }\end{array}$ & $\frac{t}{\circ}$ & 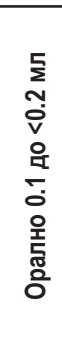 & $\stackrel{t}{\circ}$ & 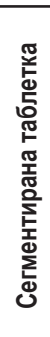 & $\stackrel{t}{\circ}$ & 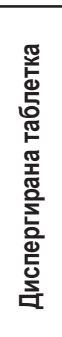 & $\stackrel{t}{\circ}$ & 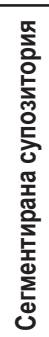 & $\frac{t}{0}$ & $\begin{array}{l}\text { 丞 } \\
\text { 5్ }\end{array}$ & to & 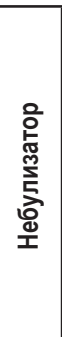 & $\frac{t}{0}$ & 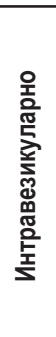 & $\frac{1}{0}$ & 음 & to \\
\hline РНКИТ & 32 & 60,4 & 18 & 34,0 & 0 & 0,0 & 3 & 5,7 & 0 & 0,0 & 0 & 0,0 & 0 & 0,0 & 0 & 0,0 & 0 & 0,0 & 0 & 0,0 & 0 & 0,0 \\
\hline OMБ & 6 & 4,0 & 2 & 1,3 & 12 & 8,0 & 107 & 71,3 & 10 & 6,7 & 0 & 0,0 & 0 & 0,0 & 0 & 0,0 & 13 & 8,7 & 0 & 0,0 & 0 & 0,0 \\
\hline РПКИТ & 68 & 31,9 & 86 & 40,4 & 5 & 2,3 & 31 & 14,6 & 17 & 8,0 & 0 & 0,0 & 3 & 1,4 & 0 & 0,0 & 1 & 0,5 & 0 & 0,0 & 2 & 0,9 \\
\hline РДБ & 14 & 11,1 & 0 & 0,0 & 0 & 0,0 & 2 & 1,6 & 36 & 28,6 & 57 & 45,2 & 1 & 0,8 & 6 & 4,8 & 7 & 5,6 & 3 & 2,4 & 0 & 0,0 \\
\hline Общо & 120 & 22,1 & 106 & 19,6 & 17 & 3,1 & 143 & 26,4 & 63 & 11,6 & 57 & 10,5 & 4 & 0,7 & 6 & 1,1 & 21 & 3,9 & 3 & 0,6 & 2 & 0,4 \\
\hline
\end{tabular}

* Процентите в реда "Общо" се отнасят до общия брой манипулации, отнесени към съответния вид манипулация.

† Процентен дял от манипулациите, извършен в различните видове болнични условия.

ОМБ - окръжна многопрофилна болница; ИВ - интравенозно; РДБ - районна детска болница; РПКИТ - районен педиатричен корпус за интензивна терапия; РНКИТ - районен неонатологичен корпус за интензивна терапия.

По време на петдневните периоди за събиране на данни не се наложи разрязване на трансдермални пластири.

Таблица 4 показва лекарствата, за които найчесто се налага корекция и нейния вид. Дадено лекарство се включваше в таблицата само ако в съответния вид обект са отчетени повече от четири корекции (от всички видове) с него. В последствие 20 различни лекарства, участвали в 54 корекции от пет различни вида, бяха изключени от Таблица 4. Лекарственият продукт, за който се установи, че най-често се налага да бъде коригиран, е хидрокортизон, както за отмерване на малки обеми за интравенозно инжектиране (РПКИТ и РНКИТ), така и за разделяне на таблетки (РДБ).

Таблица 4. Брой манипулации за лекарство (при отчитане на повече от 4 манипулации)

\begin{tabular}{|c|c|c|c|c|c|c|c|c|c|}
\hline & ИВ $<0.1$ мл & $\begin{array}{l}\text { ИВ } 0.1 \text { до } \\
<0.2 \text { мл }\end{array}$ & $\begin{array}{l}\text { Орално }<0.1 \\
\text { мл }\end{array}$ & $\begin{array}{l}\text { Орално } 0.1 \text { до < } \\
0.2 \text { мл }\end{array}$ & Небулизатор & $\begin{array}{l}\text { Таблетка (сег- } \\
\text { ментирана) }\end{array}$ & $\begin{array}{l}\text { Таблетка (дис- } \\
\text { пергирана) }\end{array}$ & Клизма & Общо \\
\hline Хидрокортизон & 28 & 25 & & & & 24 & & & 77 \\
\hline Домперидон & & & 8 & 40 & & & & & 48 \\
\hline Фентанил & 35 & 11 & & & & & & & 46 \\
\hline Диклофренак & & & & & & & 45 & & 45 \\
\hline Токофрерол & & & & 38 & & & & & 38 \\
\hline Ранитидин & 3 & 3 & & 29 & & & & & 35 \\
\hline Векурониум & & 23 & & & & & & & 23 \\
\hline Ипратропиум & & & & & 21 & & & & 0 \\
\hline Урсодеоксихолат & & & & 18 & & & & & 18 \\
\hline Фуроземид & 4 & 6 & & 6 & & & & & 16 \\
\hline Фенобарбитал & 16 & & & & & & & & 16 \\
\hline Мидазолам & 1 & 12 & & 2 & & & & & 15 \\
\hline Аспирин & & & & & & 14 & & & 14 \\
\hline \begin{tabular}{|l|} 
Левомепромазин \\
\end{tabular} & 14 & & & & & & & & 14 \\
\hline Омепразол & & & & & & 2 & 9 & & 11 \\
\hline Амлодипин & & & & 10 & & & & & 10 \\
\hline Атропин & & 6 & & & & & & & 6 \\
\hline Клобазам & & & & & & 6 & & & 6 \\
\hline Клизма "Флийт" & & & & & & & & 6 & 6 \\
\hline Левотироксин & & & & & & 5 & & & 5 \\
\hline Морфин & 5 & & & & & & & & 5 \\
\hline Суксаметониум & 4 & 1 & & & & & & & 5 \\
\hline Тейкопланин & & 5 & & & & & & & 5 \\
\hline Витамин Д & & & 5 & & & & & & 5 \\
\hline
\end{tabular}

ИВ - интравенозно 
Най-често отчитаната корекция в РДБ беше разтварянето на диклофенак диспергиращи се таблетки и приложението на пропорция от получената дисперсия. В РПКИТ най-често се налагаше отмерване на интравенозен фентанил под $0.1 \mathrm{ml}$, в РПКИТ - интравенозен фенобарбитал под $0.1 \mathrm{ml}$, а в ОМБ - отмерването на малки обеми $(<0.2 \mathrm{ml})$ домперидон за орално приложение.

\section{Дискусия}

Резултатите от проучването сочат, че коригирането на дозови форми за прилагане на прецизни дози на деца е често срещано явление в различни условия на педиатрична медицинска грижа. В малко наблюдателно проучване Skwierczynski и Conroy [7] демонстрират, че в $10 \%$ от приложението на лекарства са се налагали корекции, но те са включвали дейности като стриване на таблетки и даване на цялата дозова форма, без да се обхващат детски КИТ, неонатологични КИТ или ОМБ.

За много видове корекции отсъстват публикувани научни доказателства в подкрепа на процеca. 8 Наличните доказателствени данни като цяло насочват към потенциала за значителни вариации в приложените дози при коригиране на лекарствени продукти, но подкрепящите данни относно последствията при децата са оскъдни [9]. Според фармакопеята и други регулаторни изисквания дозовата форма следва неизменно да осигурява между 85 и $115 \%$ от посочената доза, но при повечето видове корекции приложената доза не е била изследвана и в случаите, при които има информация (най-вече при разделяне на таблетки), има основания да се смята, че този стандарт не се постига и зависи от много различни фактори, в това число марката на таблетката, пособието, използвано за разделянето и опита на извършващите корекцията $[10,11]$.

Broadhurst et al са изследвали разтварянето на таблетки аспирин във вода и са показали, че аликвотите съдържат между 23 и $147 \%$ от търсената доза [12]. В това проучване най-честата корекция на лекарство в таблетна форма беше разтваряне на диклофенак за получаване на по-малки дози чрез отмерване на аликвоти. Диклофенак диспергиращи се таблетки (Волтарол диспергиращи се таблетки от 50 mg; Новартис, Великобритания) са разрешени във Великобритания, но не и за деца и липсва информация в литературата за продукта относно точността при корекция или обема вода, в който диклофенак би се разтворил напълно.
Разделянето на таблетки на половинки или четвъртинки може да доведе до отклонение със стойност до $86 \%$ от търсената доза, като със сегменти от таблетки, които фабрично са или не са предназначени за делене, отрязани с патентован инструмент за делене се постига по-голяма прецизност в сравнение с разчупването или рязането ръчно с ножица [13].

Парацетамол супозитории от 80, 120 и 325 мг осигуряваха $69-195 \%$ от търсената половин доза при разделяне от анестезиолози. 14 Едва четири корекции на супозитории се наложиха за периода на изследването. В болниците, включени в проучването, имаше парацетамол супозитории от различни милиграми, някои от които неразрешени за употреба, с което се намаляваше необходимостта от корекция.

В настоящото изследване $25 \%$ от коригираните лекарства изискваха отмерване $<0.1 \mathrm{ml}$ или разреждане (обикновено в съотношение 1:10), за да се отмери по-голям обем. Повечето от тези отмервания бяха за лекарства за интравенозно приложение с нисък терапевтичен индекс като фентанил и фенобарбитал в неонатологични КИТ и педиатрични КИТ. Трудно е да се отмерват прецизно обеми по-малки от $0.1 \mathrm{ml} \mathrm{c} \mathrm{помощта} \mathrm{на} \mathrm{стандартни}$ спринцовки от $1 \mathrm{ml}$. Погрешно тълкуване или погрешно изчисляване при отмерването или разреждането може да доведе до десетократно по-високи дози [15]. Мъртвото пространство в накрайника на спринцовката представлява голям обем спрямо дозата, който при промиване и инжектиране или включване в разреден разтвор може да представлява сериозна грешка. Възможно е да има подобни проблеми при отмерване на обеми между 0.1 и 0.2 $\mathrm{ml}$, като непознаването на обозначенията за стотни от $1 \mathrm{ml}$ също е свързвано с лекарствени грешки. Много от лекарствата в течна форма (за интравенозно и орално приложение) се произвеждат в концентрации, позволяващи лесно изчисляване и отмерване за по-големи деца и възрастни. При употреба за новородени и бебета необходимите дози се съдържат в много малки обеми, което налага и дозови форми от по-малко милиграми или по-малко количество във флакон (за лекарства за интравенозно приложение), за да се предотвратява отмерването на доза, десетократно по-висока от нужната $[16,17]$. Регулаторната агенция на Великобритания издаде специално предупреждение относно парацетамол за интравенозно приложение [18].

При предписването на лекарства лекарите успешно са били убедени да използват дозите, посочени в рецептурни справочници като Британския национален рецептурен справочник за деца (British 
National Formulary for Children) [19]. Предписването обаче на прецизни дози въз основа $\mathrm{mg} / \mathrm{kg}$ или $\mathrm{mg} /$ $\mathrm{m} 2$ без познаване на предлаганите лекарствени форми може да доведе до опити за корекция на дозовите форми за получаване на предписаната доза. Разумно закрьгляване на дозата може да означава, че една цяла дозова форма може да бъде приложена безопасно или че обемът, който трябва да се приложи, може лесно да бъде изчислен и измерен, само ако терапевтичният индекс на лекарството е нисък [20]. Би могло да е по-безопасно да се използват препоръчани дозировъчни граници (dosage bands), съответстващи на подходящите дозови форми или лесно измерими обеми за висок терапевтичен индекс и за целите на кампании за обществено здраве [21].

За бебета и деца следва да има достьп до дозови форми, позволяващи прецизно прилагане на необходимата доза във форма, приемлива за детето. Излъчени наскоро европейски регламенти относно „по-добри лекарства за деца“ [22] задължават производителите да изследват нови лекарства при деца и да осигуряват дозови форми, съобразени с възрастта, при наличие на възможни терапевтични ползи. С това обаче се е постигнало малко за увеличение на съобразените с възрастта дозови форми на съществуващи лекарствени продукти, използвани при бебета и деца по начин, който не е посочен в кратката характеристика. Изглежда коригирането на дозови форми за осигуряване на прецизни помалки дози неминуемо ще продьлжи. При някои обстоятелства няма да се предлагат съобразени с възрастта дозови форми, а при други децата ще се избират корекции пред съответната съобразена с възрастта алтернатива (напр. биха предпочели да прегльтнат половин таблетка пред вкуса на лекарството в течна форма). Възможно е предписващият специалист да не се тревожи от евентуално неточна дозировка, воден от прагматичното схващане „по-добре една по-малко прецизна доза отколкото никаква доза“. Нашият опит показва, че много медицински специалисти споделят това виждане, когато намират основание за практическите трудности при даването на лекарства на деца, които не съдействат. Понастоящем обаче има съвсем малко информация, която да дава насоки на извършващите корекции на дозови форми, като програмата MODRIC ще предостави указания, основани на доказателства, оценка на риска и прагматизъм. Ясно $\mathrm{e}$, че наличието на повече доказателствени материали въз основа на изследвания относно прецизността на дозирането би помогнало да се установи кои лекарства, дозови форми и видове корекции следва да се поддържат и кои биха могли да нанесат вреда.
Следва да се отчетат ограниченията на настоящото изследване. В тази част на проучването не беше наблюдавано действително коригиране на дозови форми, а бяха направени заключения от единединствен опитен оценяващ въз основа на предписана доза и дозови форми, за които се знае, че са налични. При все че прякото наблюдение следва да се счита за „златен стандарт“ за определяне на корекция на дозови форми, организирането на подобно проучване за голям брой пациенти е трудно и би изисквало много наблюдатели (лична кореспонденция, R Richey). На практика е възможно извьршването на допълнителни корекции, било поради неналичие на подходяща дозова форма за осигуряване на дозата в момента на прилагането, било заради избор на пациента или защото е имало екстемпорален препарат, изготвен от фармацевта, но незаписан в рецептата и съответно не е било наложително коригирането му.

\section{Изводи}

Коригирането на дозови форми (в т.ч. отмерването на много малки обеми) за осигуряване на прецизни дозировки за бебета и деца е често срещано в първичната и вторичната медицинска практика. Малко са публикуваните доказателства, касаещи прецизността на дозата, които да служат за обосновка на практиките, но понастоящем непредлагането на специфични педиатрични лекарства и прагматичният подход на медицинските специалисти налагат практиката на коригиране да продължи. Необходими са по-нататъшни изследвания за определяне на видовете корекции и лекарствата, които да бъдат подкрепяни и които потенциално могат да нанесат вреда на децата.

\section{ОсновНИ ПОСЛАНИЯ}

Коригирането на дозови форми за получаване на прецизни по-малки дози за бебета и деца се извършва често в болниците във Великобритания.

Доказателствата в подкрепа на прецизността на дозирането при коригирането на дозовите форми са оскъдни.

Правят се опити за отмерване на много малки обеми при даването на дози на новородени и в педиатричните КИТ. Това би могло да е неточно и да доведе до погрешни изчисления.

Концентрацията на лекарствата и обемът на инжекционните ампули и флакони може да доведе до неоткрита лекарствена грешка, защото погрешно изчислени дози могат да бъдат дадени от единични опаковки, обикновено предназначени за по-големи деца или възрастни. 
Благодарности: Авторите благодарят за съдействието на Кристин Донъл (Christine Donnell) и изследователския екип за „Нежелани лекарствени реакции при деца“ (ADRIC - Adverse Drug Reactions in Children) при събирането на данни за предписани лекарства и тяхното прилагане.

Принос: Идеята и структурирането на проучването беше на AN, RR, US, CB, JC, MP и MT. $\mathrm{RR}$ организира и събра данните. AN извърши тълкуването на данните и изготви статията. RR, JF и МТ съдействаха при тълкуването на данните. Всички автори дадоха своя принос за критичната редакция на статията и съгласуването на окончателната версия.

Финансиране: Финансирането за възнаграждения на изследователите и режийни разходи беше предоставено от НИЗИ по негова програма „Изследвания в полза на пациентите“ (Research for Patient Benefit - RfPB) (реф. № на гранта PBPG-0807-13260).

Отказ от отговорност: Настоящото проучване представлява независимо изследване, възложено от НИЗИ. Изразените виждания са на авторите, без да е задължително тези виждания да се споделят от Националната здравна служба, НИЗИ или Министерството на здравеопазването.

\section{Конкуриращи се интереси: Няма.}

Гарантиране на етичност: Всички изследвания MODRIC бяха предмет на преглед от местната етична комисия и се прецени, че не се изисква официално одобрение или информирано съгласие. По места, където беше необходимо, се получаваше съгласие по научноизследователската част.

Валидиране и рецензия: Не е възлагано; извършена е външна рецензия.

Декларация за споделяне на данни: Възможно е предоставянето на допълнителни данни относно по-рядко коригирани лекарства, видове корекции и възраст на пациентите на изследователи при заявка, отправена до съответния автор.

\section{БИБЛИОГРАФИЯ}

1. Waller DG Off-label and unlicensed prescribing for children: have we made any progress? Br J Clin Pharmacol 2007;64:12. doi:10.1111/ j.1365-2125.2007.02987.x

2. Richey RH, Donnell C, Shah UU, et al. An investigation of drug manipulation for dose accuracy in paediatric practice: the MODRIC study. Arch Dis Child 2011;96:e1. doi:10.1136/ adc.2011.211243.20

3. Tan E, Cranswick NE, Rayner CR, et al. Dosing information for paediatric patients: are they really "therapeutic orphans"? Med J Aust 2003;179:195-8.
4. Paparella S Identified safety risks with splitting and crushing oral medications. J Emerg Nurs 2010;36:156-7.

5. Prot S, Fontan JE, Alberti C, et al. Drug administration errors and their determinants in pediatric in-patients. Int J Qual Health Care 2005; 17:381-9.

6. Uppal N, Yasseen B, Seto W, et al. Drug formulations that require less than $0.1 \mathrm{~mL}$ of stock solution to prepare doses for infants and children. CMAJ 2011;183: E246-8.

7. Skwierczynski C, Conroy S How long does it take to administer oral medicines to children? Paediatr Perinat Drug Ther 2008;8:145-9.

8. Richey RH, Craig JV, Shah UU, et al. The manipulation of drugs to obtain the required dose: systematic review protocol. J Adv Nurs 2011;68:2103-12.

9. Rosenzweig EB, Ivy DD, Widlitz A, et al. Long-term bosentan treatment in children with pulmonary arterial hypertension. J Am Coll Cardiol 2006;47:1915.

10. Horn L, Kuhn RJ, Kanga JF Evaluation of the reproducibility of tablet splitting to provide accurate doses for the pediatric population. J Pediatr Pharm Pract 1999;4:38-42.

11. Shah RB, Collier JS, Sayeed VA, et al. Tablet splitting of a narrow therapeutic index drug: a case with levothyroxine sodium. AAPS PharmSciTech 2010;11:1359-67.

12. Broadhurst EC, Ford JL, Nunn AJ, et al. Dose uniformity of samples prepared from dispersible aspirin tablets for paediatric use. Eur J Hosp Pharm Sci 2008;14:27-31.

13. Verrue C, Mehuys E, Boussery K, et al. Tablet-splitting: a common yet not so innocent practice. J Adv Nurs 2011;67:26-32.

14. Kim TW, Rognerud CL, Ou C-N Accuracy in the alteration of acetaminophen suppositories. Anesth Analg 2005;100:1303-5.

15. Beringer RM, Thompson JP, Parry S, et al. Intravenous paracetamol overdose: two case reports and a change to national treatment guidelines. Arch Dis Child 2011;96:307-8.

16. Chappell K, Newnam C Potential tenfold drug overdoses on a neonatal unit. Arch Dis Child Fetal Neonatal Ed 2004;89:F483-4.

17. Allegaert K, Anderson BJ, Vrancken M, et al. Impact of a paediatric vial on the magnitude of systematic medication errors in neonates. Paed Perinat Drug Ther 2006;7:59-63.

18. Anon Intravenous paracetamol (Perfalgan): risk of accidental overdose, especially in infants and neonates. Drug Saf Update 2010;3:2. http://www.mhra.gov.uk/ Safetyinformation/ DrugSafetyUpdate/CON088171 (accessed 4 Aug 2012).

19. British National Formulary for Children 2010-2011. London: BMJ Group, Pharmaceutical Press, RCPCH Publications, 2010.

20. Caldwell N, Rackham O Children's doses should be measurable (letter). Arch Dis Child 2010;95:313.

21. World Health Organization (WHO). Antiretroviral therapy for HIV infection in infants and children: towards universal access. Recommendations for a public health approach: 2010 revision. Geneva: WHO, 2010. http://www.who.int/hiv/pub/ paediatric/infants2010/en/index.html (accessed 6 Oct 2011).

22. European Parliament. Regulation (EC) No 1901/2006 of the European Parliament and of the Council of 12 December 2006 on medicinal products for paediatric use. Official Journal of the European Union 27/12/2006:L378/1-19. http:// ec.europa.eu/health/files/eudralex/vol-1/reg_2006_1901/ reg_2006_1901_en.pdf (accessed 6 Oct 2011).

\section{Адрес за кореспонденция:}

Professor Anthony Nunn

Research and Development

Alder Hey Children's

NHS Foundation Trust

Eaton Road, Liverpool

L12 2 AP, UK; A.J.

Nunn@liverpool.ac.uk 